\title{
Experimental and Numerical Study of Snuber in Hydrogen Compressor
}

\author{
M. Shiddiqur Rahman \\ Dept. of Agricultural \& Industrial Engineering, Hajee Mohammad Danesh Science \& Technology University, \\ Dinajpur, Bangladesh
}

Email: m_sq_rahman@yahoo.com

\begin{abstract}
In hydrogen production, transportation and delivery system, compression is one of the most important issues. There develop inherently pressure pulsation in reciprocating hydrogen compressing system. An experiment has been conducted to investigate the performance of snubber as pulsation damper used in reciprocating compression system. CFD analysis is applied to get the pressure values at different parts of this snubber. Regression equations are also developed for amplitude at input and output of the snubber. A comparative study of pressure and amplitude

by experiment, regression equation and CFD model are performed for 35, 40 and $45 \mathrm{~Hz}$ motor frequency. These models results are varied by $3.975 \%, 3.516 \%$ and $3.787 \%$ from the experiment for those motor frequencies. The pressure losses in the snubber are also found almost similar values by the regression equation i.e. $0.026 \%$, $0.033 \%$ and $0.018 \%$ deviations.
\end{abstract}

Keywords: Hydrogen compressing system, snubber, amplitude, RMS, CFD

\section{INTRODUCTION}

Today's modern civilization is built up by the substantial contribution of energy resources. The use of energy brings a lot of benefits but it has unwanted effects of one kind or another. Such effects can be local or widespread and have long provoked concern. The enormous scale of modern energy use has sharply increased concerns about unwanted environmental effects. Among the most significant environmental effects of energy production and consumption is the emission of greenhouse gases (carbon dioxide, methane, nitrous oxide, and others). They alter the earth's climate which is inhospitable to life. Energy-related greenhouse gas emissions make up a significant fraction of all such emissions, and the fossil fuels, are responsible for a major portion of global energy-related emissions.

For newly developed society \& increased population, energy capturing politics of different country, and possibility of damage of environment make scientists to search for alternate future fuel and fuel vehicle. Roughly $97 \%$ of all energy consumed by our cars, sport utility vehicles, vans, trucks, and airplanes is still petroleum-based. CNG and LNG which have the potential for reducing emissions of criteria pollutants and green house gases and petroleum use by spark ignition engines [1]. The recent hikes in the price of fossil fuel have added impetus to the movement towards hydrogen and other alternative fuels [2]. Choi et al., 2003 [3] found that thermal efficiency was increased with the addition of hydrogen. The physical and chemical properties of hydrogen make its utilization superior to fossil fuels. As a versatile and universal carbonless energy carrier, hydrogen is a necessary element for future energy systems aimed at being free of air pollution, $\mathrm{CO}_{2}$, and other greenhouse gases. If generated from renewable energy, hydrogen becomes the crucial link in an inexhaustible global fuel cycle based on the cleanest, most abundant, natural, and elementary substances: $\mathrm{H}_{2}, \mathrm{O}_{2}$ and $\mathrm{H}_{2} \mathrm{O}$ [4]. In integrating production planning and reactive scheduling for the optimization of a hydrogen supply network, compressor is an essential part [5]. Reciprocating compressor is used in hydrogen compressing system more for its higher pressure increasing capacity. But pressure fluctuation is inherent and resulted from reciprocating back and forth movement of piston inside the cylinder. It gives several various problems for the equipment related to the system and acting gas in it. This may cause inaccurate metering, unwanted vibrations, noises, explosions, shorten life of equipment, poor performance etc. of the hydrogen plant. Therefore, it should be lessened this pressure pulsations. Snubber or dampers are linear units designed to limit this sudden unwanted pressure pulsation. It reduces the pressure fluctuation with restoring high pressure values and also removes the impurities contained in gas [6]. Numerical analysis can give the detail information about the pressure in a system. Flow characteristics of turbulent pulsating flows in a square-cross-sectional curved duct were experimentally investigated by Sohn et al. (2007) [7]. This study was taken to find out the snubber performance in pressure fluctuation reduction of reciprocating hydrogen compression system by experiment, also by numerical simulation using CFD and regression equations.

\section{METHODOLOGY}

\subsection{Experimental Set up}

A snubber constructed by acrylic material had 1 inlet pipe, 1 outlet pipe and 1 tube shaped unit. There were 3 pressure measuring points in inlet and outlet pipe at proper distance (P1, P2, P3, P4, P5 and P6). An acryl flat plate of specified height, thickness and width was located inside the tube shaped unit at proper angle. Pressure measuring transducers were installed at each point. The inlet pipe was connected to the compressor using a small hose pipe and its outlet was exposed to the atmosphere (Fig. 1). The experiment was conducted by running the compressor and setting motor frequency at 10, 20, $30,35,40,45,50$, and $60 \mathrm{~Hz}$. Pressure value was sensed by pressure sensor, amplified and recorded in a PC using data logger.

Hydrogen gas has almost same physical characteristics with the atmospheric air. Air and hydrogen gas have almost same compressibility character. So, air compressor was used here. 


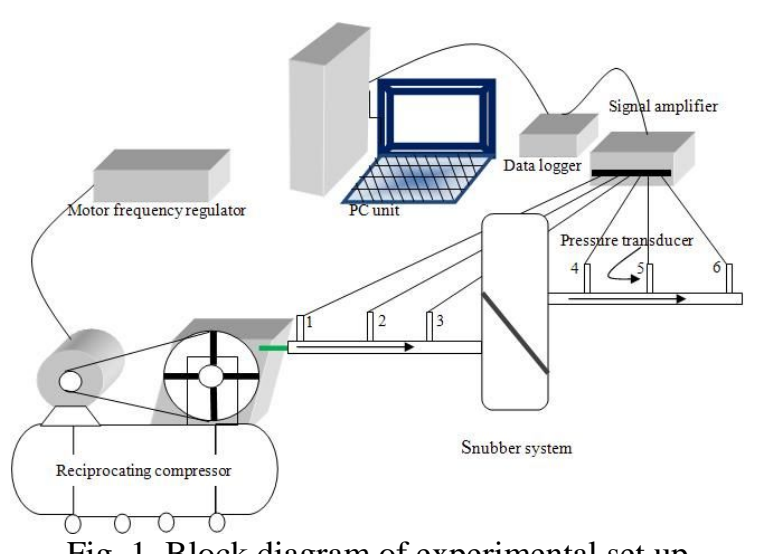

Fig. 1. Block diagram of experimental set up

\subsection{Methods}

Motor driven reciprocating pump was used in this experiment. The rotation of motor was controlled by its frequency regulator. The maximum motor rotation was 1800 rpm at maximum frequency $(60 \mathrm{~Hz})$. Then piston in the cylinder will move proportionally with the rotation. The compressing frequency can be written as:

$$
\mathrm{f}_{\text {comp }}[\mathrm{Hz}]=\mathrm{f}_{\text {set }}[\mathrm{Hz}] \times 0.214
$$

The periodic action of propelling gas through a pipe by the to and fro movement of the piston in the cylinder in reciprocating compressor cause pulsation. The piston-crankvalve mechanism generates a variable pressure, which over time creates a composite pressure wave in the suction and discharge pipe. This composite wave is made up of a number of waves. Due to periodic wave generation, multiple frequencies of pulsation are created that causes the force of vibration in the whole system.

\subsection{Pressure Characteristics Analysis}

Pressure produced by a piston in reciprocating compressor is fluctuating. Simple description of fluctuating notation is shown in Fig. 2. Same with the other gas line utilities, gas that passing through a snubber will be reduced in pressure magnitude and pressure fluctuation. It is related to the amplitude of pressure. The pressure loss and amplitude reduction can be expressed in the percentage by the Eqs. (1) (2).

$$
\begin{array}{r}
\mathrm{P}_{\text {red }}(\%)=\frac{\mathrm{P}_{\text {in }}-\mathrm{P}_{\text {out }}}{\mathrm{P}_{\text {in }}} \times 100 \% \\
\mathrm{~A}_{\text {red }}(\%)=\frac{\mathrm{A}_{\text {in }}-\mathrm{A}_{\text {out }}}{\mathrm{A}_{\text {in }}} \times 100 \%
\end{array}
$$

Data at P3 (input side) and P4 (output side) were analyzed for pressure loss and amplitude reduction. The RMS values of input and output of pressure were used for pressure loss. FFT analysis was done to on data to find out amplitude values of the pressure waves along the snubber. The resultant value of the variables was calculated by taking square root of summation of squares of all values [8]. The pressure loss and the pressure pulsation reduction were obtained by Eq. (2) and Eq. (3) from experiment.

The regression equations were developed by analyzing the experimental data for pressure magnitude calculation and pressure amplitude calculation. The pressure loss and pressure fluctuation were found from these models.

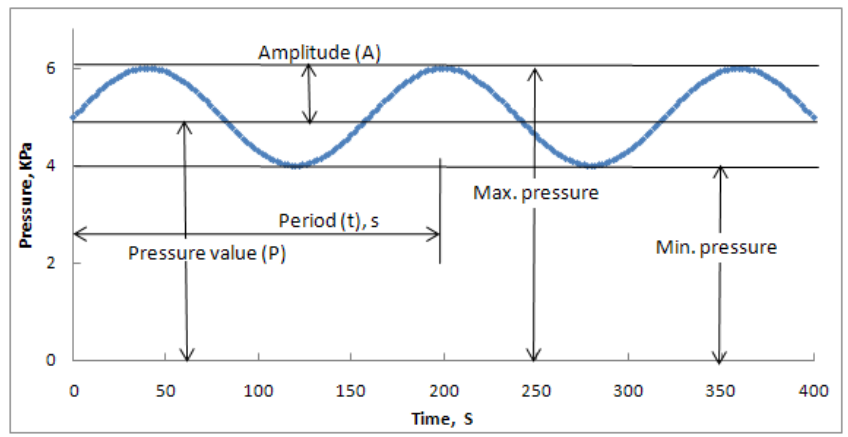

Fig. 2. Pressure fluctuation illustration

\subsection{Numerical Mothodology}

The computational code used was Star CD (Version 3.24), which solve the full 3D time dependent Navier-Stokes, continuity and energy equations using the finite volume method was chosen in this study. The turbulent flow in this investigation is considered to be transient, compressible, viscous, Newtonian and isotropic. The numerical solution involves splitting the geometry into many sub-volumes and then integrating the differential equations over these volumes to produce a set of coupled algebraic equations for the velocity components, and the pressure at the centre of each volume. The solver guesses the pressure filed and then solves the discretised form of the momentum equations to find new values of the pressure and velocity components. This process continues, in iterative manner, until the convergence criterion is satisfied.

Turbulent model was standard $\mathrm{k}-\varepsilon$ model. SIMPLE algorithm revised pressure and convection term belong to Upwind Scheme. Maximum residual tolerance was set under the 0.001 [9]. The geometry was drawn using the CATIA (V5R15) CAD package and then imported to pro-Surf as an Initial Graphics Exchange Specification file. Inlet and outlet boundary conditions for CFD were the measured pressure from the experiment using pressure sensors at inlet and outlet (Fig. 3). The model was built in a half type for the symmetrical shape of the snubber and the symmetry boundary condition was applied.

\section{RESULTS AND DISCUSSION}

\subsection{Experimental for pressure pulsation and its reduction}

Data obtained from the experiment show pressure characteristic of gas. The transient characteristic of gas both pressure values and amplitudes are shown in Fig. 3. The pictorial view shows that higher pressure at inlet (P1) and then the pressure at outlet (P6) is reduced. Shown in Figure 4 is a distribution of pressure at different points of a snubber for different motor frequency. Along the snubber, six measuring points from input and output side are chosen. The distances of point 1, 2 and 3 are 75, 250 and $450 \mathrm{~mm}$, respectively, form the outlet of the compressor and those of 740, 640 and 115 $\mathrm{mm}$ for point 4,5 and 6 , respectively. The motor was set at $60 \mathrm{~Hz}$ and then data were taken at the different measuring points and plotted against dimensionless length. Similarly for motor frequency 50, 40, 30, 20 and $10 \mathrm{~Hz}$, data were collected and plotted and found these curve form. It shows that pressure drop at points 1, 2, 3 are similar fasion but different in slope for all the motor frequency setting. At the outlet part of the snubber have also alike fashion of pressure gradient as inlet parts but with less slope for each pressure line. 


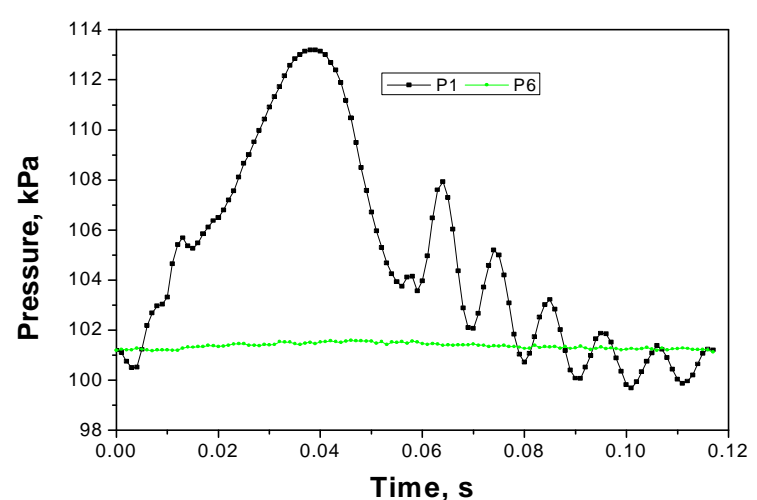

Fig. 3. Inlet and outlet boundary condition

When motor frequency is set at $30 \mathrm{~Hz}$, the pressure at dimesionless length $0,0.16827,0.36058,0.63942,0.83173$ and 1 are 103.4879, 103.1812, 102.8375, 101.849974, 101.528225 and $101.325935 \mathrm{kPa}$, respectively. The pressure drop between point 3 and 4 for each motor frequency is more than the other measuring points due to the main body of snubber. For higher motor frequency, the pressure reduction rate is also higher. The pressure gradient for motor frequency $60 \mathrm{~Hz}$ is the highest and lowest gradient is found at $10 \mathrm{~Hz}$ motor frequency.

When pressured gas is allowed to flow through the snubber system, its pulsation is downed along with its pressure value. For different pressured gas, pressure loss increases with the gas pressure. The percentages of pressure losses are $0.06778 \%, 0.4752 \%, 0.9603 \%, 1.5329 \%, 1.9633 \%$, and $2.4794 \%$ for $10,20,30,40,50$, and $60 \mathrm{~Hz}$ motor frequency of the compressor operation. Maximum $2.4794 \%$ pressure loss is recorded in the snubber of this experiment. It shows the linear relationship with the pressure of gas (Fig. 4).

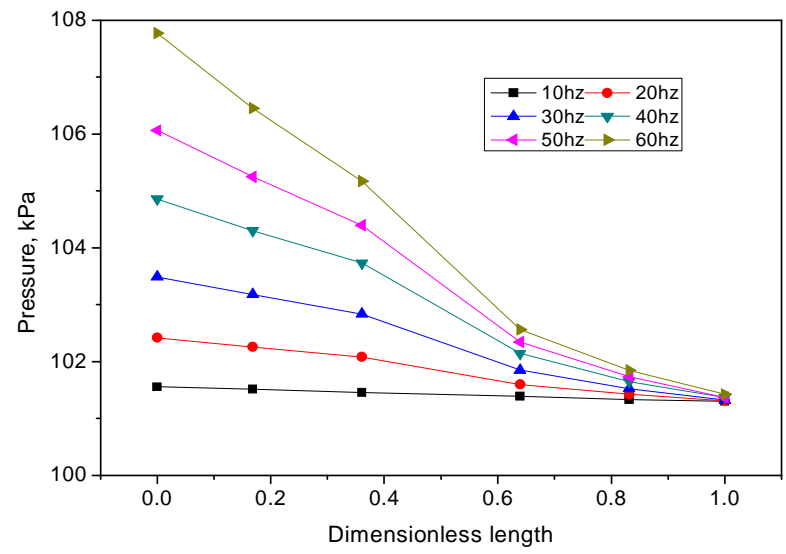

Fig. 4. Pressure distribution at different location

Measurement of amplitude at the either side of the snubber aregive us information about performance of snubber. Different gas pressure is preduced by the operation of compressor with motor at different frequencies. Each input amplitude and output amplitudes are in non-linear / polynomial relationship with the gas pressure. The percentages of amplitude reduction are 58.4604, 55.9466, $58.2487,57.0261,56.8709$ and $57.2832 \%$ for $10,20,30,40$, 50 , and $60 \mathrm{~Hz}$ motor frequency. So, it can be concluded that this snubber is able to reduce $55.9466 \%$ to $58.2487 \%$ pressure pulsation (Fig. 9).

Measurement of amplitude at the either side of the snubber aregive us information about performance of snubber. Different gas pressure is preduced by the operation of compressor with motor at different frequencies. Each input amplitude and output amplitudes are in non-linear / polynomial relationship with the gas pressure. The percentages of amplitude reduction are 58.4604, 55.9466, $58.2487,57.0261,56.8709$ and $57.2832 \%$ for $10,20,30,40$, 50 , and $60 \mathrm{~Hz}$ motor frequency. So, it can be concluded that this snubber is able to reduce $55.9466 \%$ to $58.2487 \%$ pressure pulsation (Fig. 6).

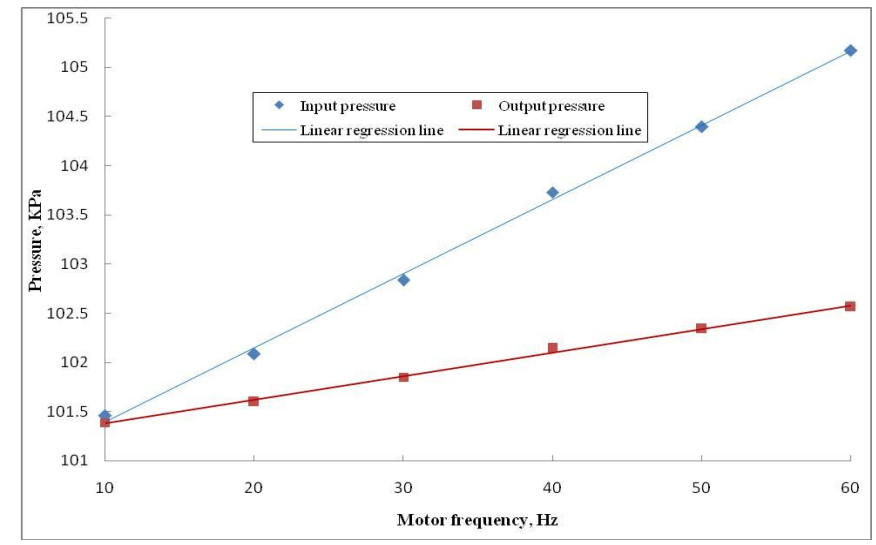

Fig. 5. Input and output pressure at snubber

\subsubsection{Regression equation}

The motor frequency is plotted on $\mathrm{X}$-axis and the corresponding input [P3] and output [P4] pressure obtained from experiment is plotted on Y-axis as shown in Fig. 5. It is observed that data points on the graph represent straight line for both input and output pressure. But the input pressure line have more slope than the output pressure. A straight line is found to be best fitted line on the data points of the input pressure. The coefficient of determination is approximately unity $\left(\mathrm{R}^{2}=0.998\right)$ that indicates a very good fit. The calibration equation of the measurement of input pressure is as eq. (3). Similarly, a linear regression line (eq. 4) is finally found to be best fitted on the output data points with coefficient of determination $\left(\mathrm{R}^{2}=0.998\right)$.

$$
\begin{aligned}
& y=0.0754 x+100.6396, R^{2}=0.998 \\
& y=0.0240 x+101.14099, R^{2}=0.998
\end{aligned}
$$




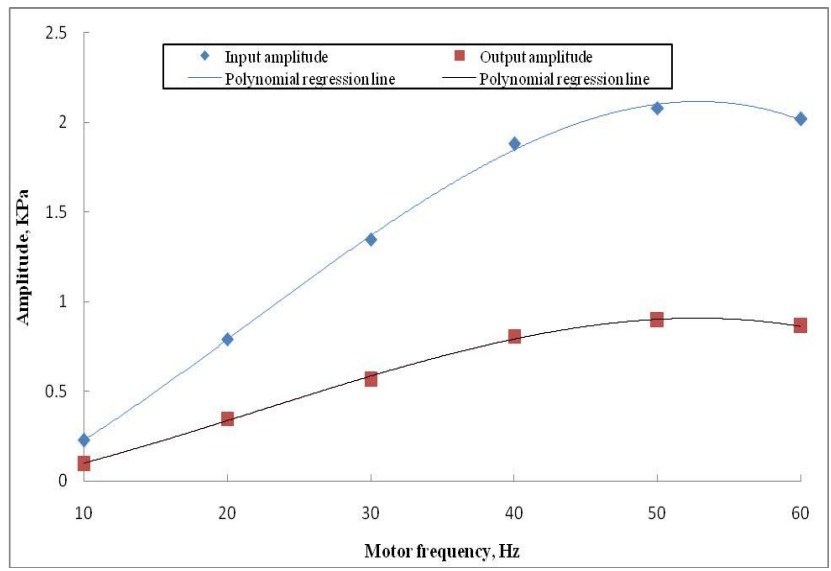

Fig. 6. Pressure amplitude at snubber

The functional relationship between the motor frequency and input \& output pressure amplitude is illustrated in Fig. 6. Input and output pressure amplitude data against motor frequency show non-linear relationship for both the cases. A third-degree polynomial regression lines are found to be best fitted for input and output pressure amplitudes. The input pressure amplitude is correlated with the motor frequency by the following eq.5 with high coefficient of determination $\left(\mathrm{R}^{2}\right.$ $=0.990$ ) which indicates a good fit. In case of output pressure amplitude, data points have a good fit with the coefficient of determinatio, $\mathrm{R}^{2}=0.998$.

$$
\begin{aligned}
& y=-0.0008 x^{2}+0.0951 x-0.7023, R^{2}=0.990 \\
& y=-0.0003 x^{2}+0.0407 x-0.3011, R^{2}=0.988
\end{aligned}
$$

The input and output amplitude for various motor frequency can be calculated by the regression equations. Table 1 shows the comparison of regression equation, experiment and CFD simulation result for amplitude reduction at the snubber at 35 , 40 and $45 \mathrm{~Hz}$ motor frequency. The input and output pressure amplitude predicted by regression equations are $1.6462 \mathrm{KPa}$ and $0.7559 \mathrm{KPa}$; $1.8217 \mathrm{KPa}$ and $0.8469 \mathrm{KPa}$; and 1.9572 $\mathrm{KPa}$ and $0.9229 \mathrm{KPa}$, respectively corresponding to these motor frequencies. Input amplitudes are found 1.5028, 1.6490 $\mathrm{KPa}$ from experiment and CFD simulation, respectively. Similarly, they have output amplitude as $0.6303,0.7200 \mathrm{KPa}$ by experiment and CFD, respectively, for $35 \mathrm{~Hz}$ motor frequency. The percentages of amplitude reductions are $54.082 \%, 58.057 \%$ and $56.337 \%$ by regression equation, experiment and CFD simulation. The variations of percentages of amplitude reduction from experiment are 3.975, 1.720 for model and CFD simulation, respectively. The percentages of amplitude reduction are $53.510 \%, 57.026 \%$, $57.657 \%$ for model, experiment and CFD simulation, respectively, at $40 \mathrm{~Hz}$ motor frequency. The $52.846 \%$, $56.633 \%$ and $57.158 \%$ amplitude reduction are found for 45 $\mathrm{Hz}$ by model, experiment and CFD, respectively. The deviation of percent amplitude reduction by model from the experiment for 35,40 and $45 \mathrm{~Hz}$ are $3.975 \%, 3.516 \%$ and $3.787 \%$ i. e. not more than $3.975 \%$ and those from CFD are $2.255 \%, 4.147 \%$ and $4.312 \%$ which is not more than $4.312 \%$. CFD simulation and model calculation for pressure amplitude values are very close to each other. It indicates regression equation's credibility and efficacy, and it can be applied for calculating pressure amplitude and amplitude reduction for any setting of motor frequency run by reciprocating compressor.
Table 1. Comparison of regression equation, experiment and CFD

\begin{tabular}{|c|c|c|c|c|c|}
\hline $\begin{array}{l}\text { Test } \\
\text { type }\end{array}$ & $\begin{array}{c}\text { Motor } \\
\text { freq., } \\
\mathrm{Hz}\end{array}$ & $\begin{array}{c}\text { Input } \\
\text { ampli., } \\
\mathrm{KPa}\end{array}$ & $\begin{array}{c}\text { Output } \\
\text { ampli., } \\
\mathrm{KPa}\end{array}$ & $\begin{array}{l}\% \text { ampli. } \\
\text { reduction, } \\
\mathrm{KPa}\end{array}$ & $\begin{array}{l}\text { Dev. } \\
\text { from } \\
\text { Exp }\end{array}$ \\
\hline Reg. Eq. & \multirow{3}{*}{35} & 1.6462 & 0.7559 & 54.082 & 3.975 \\
\hline Exp & & 1.5028 & 0.6303 & 58.057 & \\
\hline CFD & & 1.6490 & 0.7200 & 56.337 & 1.720 \\
\hline Reg. Eq. & \multirow{3}{*}{40} & 1.8217 & 0.8469 & 53.510 & 3.516 \\
\hline Exp & & 1.8810 & 0.8083 & 57.026 & \\
\hline CFD & & 1.7449 & 0.7388 & 57.657 & -0.631 \\
\hline Reg. Eq. & \multirow{3}{*}{45} & 1.9572 & 0.9229 & 52.846 & 3.787 \\
\hline Exp & & 1.8821 & 0.8162 & 56.633 & \\
\hline CFD & & 1.8930 & 0.8110 & 57.158 & -0.525 \\
\hline
\end{tabular}
simulation for amplitude reduction

Table 2 represents the performance of model over experiment and CFD simulation for pressure loss at different compressor running. When the motor will run at 35,40 and $45 \mathrm{~Hz}$, the regression equation presents the input and output pressure as $103.2786 \mathrm{kPa}$ and $101.9809 ; 103.6556 \mathrm{kPa}$ and $102.1009 \mathrm{kPa}$; and $104.0326 \mathrm{kPa}$ and $102.2209 \mathrm{kPa}$, respectively. Data analyses for input and output pressure by experiment and by CFD are 103.4040, 102.0774 and 103.5080, 102.1170; for 35 $\mathrm{Hz} ; 103.7319,102.1418$ and $103.7820,102.1585$; for $40 \mathrm{~Hz}$, 104.1653, 102.3322 and 104.2700, 102.4110; for $45 \mathrm{~Hz}$, respectively. The percentages of pressure loss are $[1.257 \%$, $1.283 \%, 1.344 \%],[1.500 \%, 1.533 \%, 1.564 \%]$ and $[1.741 \%$, $1.760 \%, 1.783 \%$ ], respectively for model, experiment and CFD for 35, 40 and $45 \mathrm{~Hz}$, respectively. It is observed that regression equation match well with experiment and CFD simulation. The maximum percentage of pressure loss deviation of model from experiment is $0.033 \%(0.026 \%$, $0.033 \%$, and $0.018 \%$ for 35,40 and $45 \mathrm{~Hz}$ ). The CFD simulation and experimental values are varied by $0.087 \%$, $0.064 \%$ and $0.041 \%$ pressure loss for 35,40 and $45 \mathrm{~Hz}$, respectively. It can be seen that the regression equation and CFD simulation for pressure loss value is very close. It represents good performance of the regression equation.

Table 2. Comparison of regression eq., experimental and numerical

\begin{tabular}{|c|c|c|c|c|c|}
\hline $\begin{array}{l}\text { Test } \\
\text { type }\end{array}$ & \begin{tabular}{|c|} 
Motor \\
freq., \\
$\mathrm{Hz}$ \\
\end{tabular} & $\begin{array}{c}\text { Input } \\
\text { pressure, } \\
\mathrm{KPa} \\
\end{array}$ & $\begin{array}{c}\text { Output } \\
\text { pressure, } \\
\mathrm{KPa} \\
\end{array}$ & $\begin{array}{c}\% \\
\text { pressure } \\
\text { loss, KPa } \\
\end{array}$ & $\begin{array}{l}\text { Dev. } \\
\text { from } \\
\text { Exp } \\
\end{array}$ \\
\hline Reg. Eq. & \multirow{3}{*}{35} & 103.2786 & 101.9809 & 1.257 & 0.026 \\
\hline Exp & & 103.4040 & 102.0774 & 1.283 & \\
\hline CFD & & 103.5080 & 102.1170 & 1.344 & -0.061 \\
\hline Reg. Eq. & \multirow{3}{*}{40} & 103.6556 & 102.1009 & 1.500 & 0.033 \\
\hline Exp & & 103.7319 & 102.1418 & 1.533 & \\
\hline CFD & & 103.7820 & 102.1585 & 1.564 & -0.031 \\
\hline Reg. Eq. & \multirow{3}{*}{45} & 104.0326 & 102.2209 & 1.741 & 0.018 \\
\hline Exp & & 104.1653 & 102.3322 & 1.760 & \\
\hline CFD & & 104.2700 & 102.4110 & 1.783 & -0.023 \\
\hline
\end{tabular}
for pressure loss in the snubber

\subsubsection{CFD simulation of pressure in the snubber}

Experimental pressure value at P2 and at P5 with the CFD simulated corresponding values are presented in Fig. 7. Simulated pressures at P2 and P5 are almost same behavior that of experimental. Similarly, at P3 and P4 the magnitude of pressures for CFD prediction and experiment are like Fig. 8. All these CFD calculated pressures at P2, P3, P4, and P5 are well match with the pressure found in experiment. So, now 
we can allow the pressure distribution calculation of CFD to describe the pressure in the various points in the snubber system.

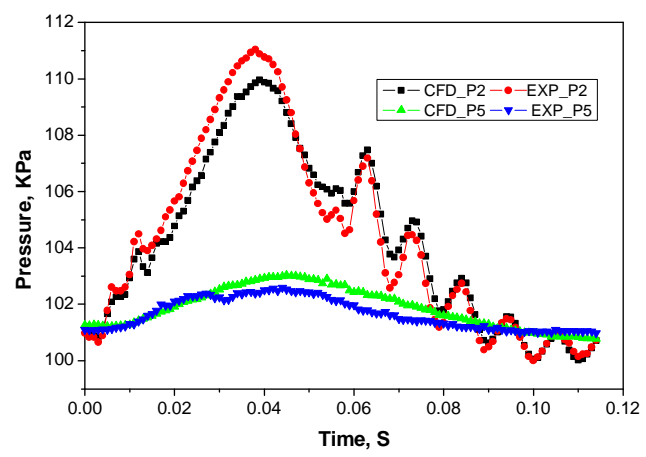

Fig. 7. Comparison of CFD simulated pressure with experiment for $\mathrm{P} 2$ and $\mathrm{P} 5$

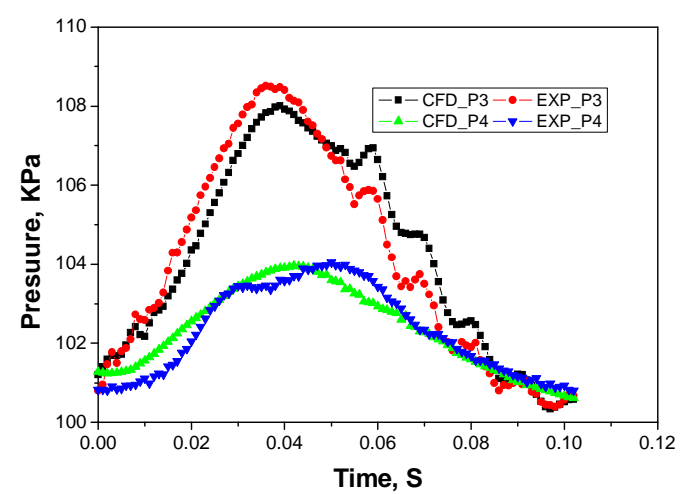

Fig. 8. Comparison of CFD simulated pressure with experiment for $\mathrm{P} 3$ and $\mathrm{P} 4$

Fig. 9 explains the pressure values in the snubber system for $40 \mathrm{~Hz}$ motor frequency with pictorial, numerical, maximum and minimum values. High pressure is developed at the beginning in the inlet pipe and it dwindles gradually with length of pipe. But there is sudden pressure drop from P3 to P4 due to snubber main body. Inside the snubber main unit, the entrance point of snubber, below the buffer parallel to inlet pipe, exit pipe entrance has high pressure zones.

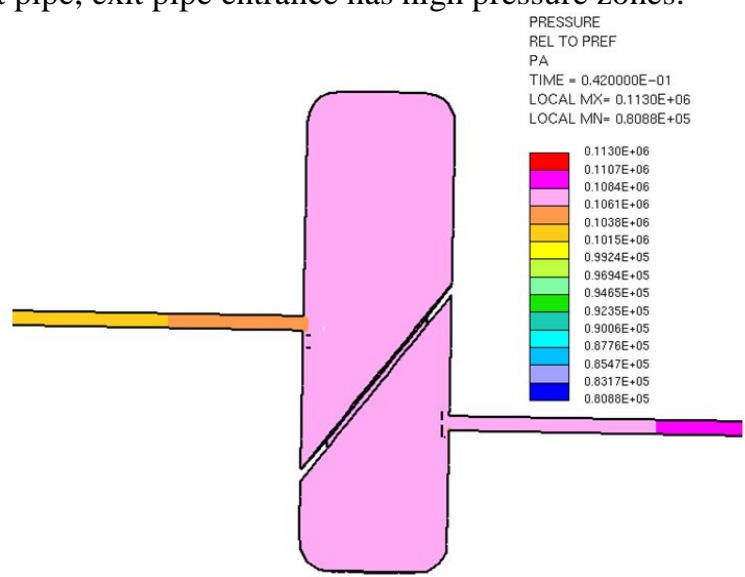

Fig. 9. Pressure distribution inside the snubber at different time (cfd simulation) at $40 \mathrm{~Hz}$

At the beginning of time step, there form different pressures at various points but at end of time step it is demolished and then pressure is become well distributed throughout the snubber except some locations. At the time step for $\mathrm{t}=0.42 \mathrm{E}-01 \mathrm{~s}$, the maximum and minimum pressure are $0.1130 \mathrm{E}+06 \mathrm{~Pa}$ and $0.8088 \mathrm{E}+05 \mathrm{~Pa}$, respectively at the entrance and exit point in the snubber system. Detail pressure distribution with graphical and numerical values at various time steps can be obtained by selecting specific zone of the snubber model.

\section{CONCLUSION}

Attenuation of pressure fluctuation in reciprocating hydrogen compression system is essential in hydrogen chain economy. Instantaneous measurement of pressure at various points in the snubber system can give the pulsation reduction information for this section. Numerical solution of continuity, momentum, energy equations using CFD is a now-a-days tool to calculate pressure distribution in a system. Regression equation can also predict the pressure information from which pressure pulsation and pressure loss can be obtained. In this study, the pressure pulsation data predicted by regression equation for 35, 40 and $45 \mathrm{~Hz}$ motor frequency are presented pressure pulsation reduction as $54.082 \%, 53.510 \%, 52.846 \%$, respectively, which are very close to experiment and those of CFD simulation. The percentages of pressure losses are estimated as $1.257 \%$ and $1.344 \% ; 1.500 \%$ and $1.564 \%$; $1.741 \%$ and $1.783 \%$ for regression equation and CFD simulation for 35,40 and $45 \mathrm{~Hz}$ motor frequency, respectively. They are found by experiment as $1.283 \%$, $1.533 \%$ and $1.760 \%$. As regression equation have almost same prediction of amplitude of pressure and pressure loss like CFD, so, this tool also can be used as the fastest estimation tool for pressure pulsation reduction and pressure loss at the snubber in hydrogen compression system.

\section{REFERENCES}

[1] Lee K. H., Lee C. S., Ryu J. D., Choi G. M., (2002), Analysis of combustion and flame Propagation Characteristics of LPG and Gasoline Fuels by Laser Deflection Method, KSME International Journal, Vol. 16. No. 7. pp. 935-941.

[2] Shayegan S. A., Hart D., Pearson P., Joffe D.,(2006), Analysis of the cost of the hydrogen structure for buses in London, Journal of Power Sources, 157(2), pp. 862-874.

[3] Choi H. C., Han S. B., Chung Y. J., (2003), The Effect of Hydrogen Enrichment on Exhaust Emissions and Thermal Efficiency in a LPG fuelled Engines, KSME International Journal, Vol. 17. No.8. pp.11961202.

[4] Salvador M. A., Gene D. B., Joel M. F., Francisco E. L., (2006), Vehicular storage of hydrogen in insulated pressure vessels, International Journal of Hydrogen Energy, Vol. 31, pp. 2274-2283.

[5] Heever S. A., Grossman I. E., (2003), A strategy for the integration of production planning and reactive scheduling in the optimization of hydrogen supply network, Journal of Computers and Chemical Engineering, Vol. 27, pp. 1831 1839.

[6] API, (1995), American Petroleum Institute, Reciprocating Compressors for Petroleum, Chemical and gas Industry Services. API Standard 618. American Petroleum Institute, Washington, D. C.

[7] Sohn H. C., Lee H. N., Park G. M., (2007), A study of the flow characteristics of developing turbulent pulsating flows in a curved duct, Journal of Mechanical Science and Technology, Vol. 21, pp.2229-2236.

[8] Origin lab Co., (2003), Origin Reference v7.5. FFT Mathematical Description, 2003.

[9] CD Adapco Group, (2004), Methodology Star CD Version 3.24, CD Adapco Group, 2004. 